\title{
Guidelines for SARS-CoV-2 infection clinical management according to Mexico's reality
}

\section{Una guía para el manejo clínico de la infección por SARS-CoV-2 acorde con la realidad de México}

René A. Flores-Franco*

Department of Internal Medicine, Zone 1 Regional General Hospital, Instituto Mexicano de Seguro Social, Chihuahua, Mexico

I read with interest the article on the guidelines for SARS-CoV-2 infection clinical management, where therapeutic options for patients infected by said virus, which were formulated considering their applicability in daily practice, both institutionally and in the private sphere are reasonably well explained ${ }^{1}$. At more than 1 year of the onset of the pandemic at the Mexican Institute of Social Security, there are still no antivirals with proven clinical effectiveness, and only systemic steroids are available to fight the cytokine storm. In private practice, insurance companies do not cover the expenses generated by the use of remdesivir, baricitinib, or tocilizumab, regarded as drugs in experimental phase.

Given the lack of a scientific foundation, philosophical foundation has been resorted to; for example, some consider that we are living a scenario that is emotionally and socially risky for scientific and medical objectivity in the search for new therapeutic alternatives to help patients ${ }^{2}$. However, could this scenario not be an epistemologically paralyzing obstacle in the search for new treatments? The crisis situation can lead to dark alleys, one of which may be blameworthy inaction or omission.

However, there are no few philosophers of science who have questioned scientific objectivity as an absolute, and more so if that objectivity is understood as disdain for experience. Already Thomas S. Khun, in "The Structure of Scientific Revolutions," made it clear how certain paradigms are imposed on the scientific community and generate that which is called "normal science," which systematically opposes any possibility or any hypothesis outside the paradigm that is socially accepted by the scientific community itself, most of the times legitimized by research with limitations.

Scientific knowledge does not emerge or come from an ethereal and intangible region such as the Platonic world of ideas. Its starting point is experience. There is no ethical justification for speculating with patients, and neither is there an ethical justification for not considering potentially useful alternatives. After all, with fairness and good logic, inactions and omissions are also actions. There is also the sin of omission. And although they cannot be anticipated, they can be verified when they have already occurred, and more than 200,000 deaths in this country clearly show the possible scope of some inactions.

With all of the above, within the context of our reality in professional practice, an opportunity should be given to not yet "scientifically" explored drugs, but that are potentially beneficial in the treatment of patients infected with SARS-CoV-2. Drugs with better access, low cost, effective, and that, adequately indicated, have an acceptable safety profile. Institutional shortages and lack of support from insurance companies have forced to urgently search for alternatives for patients with resistance to systemic steroids, especially for drugs with immunomodulatory activity with objectively demonstrable effectiveness in peripheral
Correspondence:

*René A. Flores-Franco

E-mail: rflores99@ @rontomail.com

0016-3813/@ 2021 Academia Nacional de Medicina de México, A.C.. Published by Permanyer. This is an open access article under the CC BY-NC-ND license (http://creativecommons.org/licenses/by-nc-nd/4.0/). 
blood inflammatory parameters: lymphocyte count and C-reactive protein and interleukin 6 levels.

Methotrexate has met these expectations and its usefulness has been suggested since the beginning of the pandemic ${ }^{3}$. Based on the fact that, in other autoimmune diseases that are treated with methotrexate the probability of hospitalization or mortality in case of becoming infected with SARS-CoV-2 does not increase, it could be concluded that its use does not complicate the course of the disease. At low doses, methotrexate blocks the intracellular Jak/Stat pathway involved in the transduction of information generated by various cytokines and controls immune and inflammatory responses.
Within a context of scientific uncertainty and external pressures, the clinician in Mexico has to make decisions regarding the treatment of the SARS-CoV-2-infected patient that hardly would be included in any clinical guidelines.

\section{References}

1. García-Álvarez JL, García-Vigil JL. Guidelines for clinical management of SARS-CoV-2 infection. Gac Med Mex. 2020;156:576-83.

2. Martínez-Michel O, Romero-Thirión II. El uso de tocilizumab en pacientes con COVID-19. Consideraciones metodológicas y éticas. Neumol Cir Torax. 2021;80:6-8.

3. Rajaiah R, Abhilasha KV, Shekar MA, Vogel SN, Vishwanath BS. Evaluation of mechanisms of action of re-purposed drugs for treatment of COVID-19. Cell Immunol. 2020;358:104240. 